\title{
Study of Preoperative Antiviral Treatment of Patients with HCC Negative for HBV-DNA
}

\author{
XIAO-FANG LIU, TONG ZHANG, KUN TANG, LU-LU SUI, GANG XU and QIANG LIU \\ Department of Hepatobiliary Surgery, Affiliated Yantai Yuhuangding Hospital, \\ Qingdao University Medical College, Yantai, P.R. China
}

\begin{abstract}
Aim: To study preoperative HBV-DNA negative $H B V$-related hepatocellular carcinoma $(H C C)$ which was reactivated after surgery and could influence liver function and HCC recurrence. Patients and Methods: Patients were divided into two groups according to preoperative antiviral therapy status. The control group comprised of 102 preoperative HBV-DNA-negative patients who had not undergone antiviral therapy before surgery. In the treatment group, all HBV-DNA-negative patients $(n=63)$ received entecavir 3-5 days before surgery and for 12 months after surgery. Patients were followed-up regularly, during the preoperative period, and at 1, 3, 6, 12, 18, 24, 30 and 36 months postoperatively. The data for the two groups were analyzed including the level of $H B V-D N A$ and $H B V-D N A$ activation; liver function; 1-, 2- and 3-year survival rate; cumulative survival time; and tumor recurrence. Results: Liver function in the treatment group was better than that of the control group 12 months after surgery. Compared to the control group, total bilirubin in the treatment group was significantly better at 6 and 12 months after surgery $(p<0.05$ and $p<0.001$, respectively). Serum albumin, alanine aminotransferase and prothrombin time in the treatment group was significantly better than that of controls 12 months after surgery $(p<0.001)$. In the treatment group, two cases $(3.17 \%)$ had $H B V-D N A$ activation while there were 13 cases $(12.75 \%)$ with $\mathrm{HBV}$-DNA activation in the control group $(p<0.05)$. There were 51 cases with tumor recurrence in the control group, that was statistically significantly higher than recurrent cases in the treatment group $(p<0.05)$. Postoperative 1-, 2- and 3-year cumulative overall survival rates were $94.12 \%, 81.37 \%$ and $52.94 \%$, respectively, for the
\end{abstract}

Correspondence to: Dr. Xiao-Fang Liu, Department of Hepatobiliary Surgery, Affiliated Yantai Yuhuangding Hospital, Qingdao University Medical College, Yantai 264000, P.R. China. Tel: +86 5356691999, Fax: +86 5356240341, e-mail: Liu634@263.net

Key Words: Antiviral treatment, hepatocellular carcinoma (HCC), HBV-DNA. control group and 93.65\%, $77.78 \%$ and $71.43 \%$, respectively, for the treatment group $(p=0.006)$. There was no statistically significant difference in disease-free survival between the two groups $(p=0.231)$. Conclusion: Antiviral treatment of $\mathrm{HBV}$-related $\mathrm{HCC}$ with negative $\mathrm{HBV}$-DNA is beneficial to liver function, coagulation function, disease control, prevention of tumor recurrence, improvement of patient quality of life, reduces the death rate and prolongs survival duration.

There is a high incidence of primary hepatocellular carcinoma (HCC) and hepatitis B virus (HBV) in China, with approximately $90 \%$ of patients with HCC having HBV infection. Nowadays, surgical treatment is considered the optimal method for therapy of HCC although postoperative occurrence and metastasis rates are still high. This appears to be related to a number of factors, including the tumor size, location, differentiation, age, etc. The state of HBV replication is the most important factor influencing HBV-related HCC recurrence. However, anti-HBV therapy is often overlooked in the process of HCC treatment, especially in the perioperative period. Many studies demonstrated that HCC with a high HBV-DNA level also showed increased invasiveness and recurrence. Therefore, a consensus has been reached that antiviral therapy for HBV-DNA-positive HCC should be conventionally used after surgery. With a deeper understanding of liver cancer recurrence, this common clinical problem has gradually attracted the attention of scholars to the idea of $\mathrm{HBV}$ reactivation after surgery for HBV-related HCC in patients preoperatively HBV-DNA-negative, which could influence liver function and $\mathrm{HCC}$ recurrence.

\section{Patients and Methods}

Clinical data. From June 2008 to December 2013 at Yantai Yuhuangding Hospital of Qingdao University Medical College, 165 patients who were diagnosed with HBV-related liver cancer were enrolled in our study. There were 108 males and 59 females with a mean age of $58.3 \pm 7.5$ years who underwent radical liver cancer resection. The diagnosis of HBV-related liver cancer was according to the standard of primary liver cancer. Study inclusion criteria: i) 
Table I. Comparison of general characteristics of the two groups before the study.

\begin{tabular}{|c|c|c|c|c|}
\hline Characteristic & Treatment group, $\mathrm{n}=63$ & Control group, $\mathrm{n}=102$ & $\chi^{2}$ or $t$-value & $p$-Value \\
\hline Male/female, $\mathrm{n}$ & $43 / 20$ & $67 / 35$ & 0.116 & 0.734 \\
\hline Median age (range), years & $58.4(43-67)$ & $57.6(41-68)$ & 1.654 & 0.531 \\
\hline \multicolumn{5}{|l|}{ AFP, $n$} \\
\hline$\geq 400 \mathrm{IU} / 1$ & 16 & 30 & 0.312 & 0.576 \\
\hline$<400 \mathrm{IU} / 1$ & 47 & 72 & & \\
\hline \multicolumn{5}{|l|}{ BCLC stage, $\mathrm{n}$} \\
\hline $\mathrm{O}$ & 13 & 21 & 0.000 & 0.994 \\
\hline A & 50 & 81 & & \\
\hline
\end{tabular}

AFP, Alpha fetoprotein; BCLC, Barcelona clinic liver cancer.

no treatment before surgery which might affect the prognosis, such as chemotherapy, radiation therapy or biological therapy, etc. ii)confirmed with HBV infection and without HCV infection, with a negative HBV-DNA result. iii) liver cancer resection, with intraoperative blood transfusion was $\leq 200 \mathrm{ml}$. iv) HCC confirmed by pathological examination. v) Barcelona Clinic Liver Cancer (BCLC) stage $\mathrm{O}$ or $\mathrm{A}$.

Operative methods. The tumors, which were all located in one lobe or segment, were $3-7.5 \mathrm{~cm}$ in diameter and the number of tumors was three or fewer. Sub-segmental hepatectomy was carried out in 67 cases, segmental hepatectomy in 36, hepatic left lateral lobectomy in 28 and left hepatectomy in 34 .

Study group. According to preoperative antiviral therapy, all patients were divided into two groups. In the control group, there were 102 patients preoperatively HBV-DNA negative who had not undergone any antiviral therapy before surgery. However, in the postoperative follow-up, HBV-DNA was activated and entecavir was then administered. In the treatment group, all HBV-DNA-negative patients $(n=63)$ received entecavir 3-5 days before surgery and for 12 months after surgery. All patients gave their informed consent for participation in this study.

Follow-up data. Patients were contacted regularly by telephone, letter, outpatient clinic, etc. in the preoperative period, and at 1,3, $6,12,18,24,30$ and 36 months postoperatively.The data were collected regarding the following: i) detection of HBV-DNA and the activation of HBV-DNA; ii) evaluation of postoperative liver function; iii) detection of alpha fetoprotein (AFP) and computed tomographic or magnetic resonance imaging for examination of tumor recurrence; iv) the endpoint was at death or 3 years after surgery. The identification of HBV-DNA reactivation was considered to be when preoperative HBV-DNA was less than $1.0 \times 10^{3} \mathrm{IU} / \mathrm{ml}$ and postoperative HBV-DNA was $1.0 \times 10^{3} \mathrm{IU} / \mathrm{ml}$ or greater. The data from the two groups were analyzed including the levels of HBVDNA and HBV-DNA activation, liver function, 1-, 2- and 3-year survival rate, cumulative survival time, and tumor recurrence.

Test methods. Liver function was examined by the American Beckman automatic biochemical analyzer (Beckman Corp, Atlanta, GA, USA) and its auxiliary reagents. HBV-DNA loads were tested using nucleic acid fluorescent quantitative polymerase chain
Table II. Comparison of liver function of the two groups before surgery.

\begin{tabular}{lcccc}
\hline Group & TBIL (umol/l) & ALB (g/l) & ALT (IU/l) & PT (s) \\
\hline Treatment (n=63) & $26.6 \pm 8.5$ & $40.3 \pm 3.5$ & $37.3 \pm 16.1$ & $12.1 \pm 1.1$ \\
Control (n=102) & $25.3 \pm 7.6$ & $39.2 \pm 3.2$ & $36.8 \pm 17.3$ & $12.3 \pm 1.2$ \\
$t$-Value & 1.019 & 2.069 & 0.185 & 1.974 \\
$p$-Value & 0.1546 & 0.835 & 0.853 & 0.285 \\
\hline
\end{tabular}

TBIL: Total bilirubin, ALB: albumin, ALT: alanine aminotransferase, PT: prothrombin time.

reaction using reagents produced by Guangzhou Da'an Gene Diagnosis Center (Da'an Gene Corp, Guangdong, China), where the lower detection limit was $10^{3} \mathrm{IU} / \mathrm{ml}$. If the patient died during the observation period, the study was stopped and all data collected to that point analyzed.

Statistical methods. The data were analyzed using SPSS 19.0 software package (IBM Corp., Armonk, NY, USA). The measurement data are reported as the mean \pm standard deviation and compared using Student's $t$-test. The enumeration data was represented by composition ratio and compared by chi-squared test. Disease-free survival was calculated by the Kaplan-Meier method. The differences between the two groups were assessed using the log-rank method and a value of $p<0.05$ was considered statistically significant.

\section{Results}

Comparison of general characteristics of the two groups before the study. The general characteristics for the two groups included gender, age, AFP and BCLC stage. There was no statistical difference between the two groups $(p>0.05)$ (Table I).

Comparison of liver and coagulation functions of the two groups before surgery. Comparison of liver function and coagulation function included total bilirubin (TBIL), albumin (ALB), alanine aminotransferase (ALT) and prothrombin time 
Liu et al: Perioperative Anti-HBV Therapy in Hepatocellular Carcinoma

Table III. Comparison of operative and pathological characteristics of the two groups.

\begin{tabular}{|c|c|c|c|c|c|c|c|c|c|c|}
\hline \multirow[t]{2}{*}{ Group } & \multicolumn{2}{|c|}{$\begin{array}{l}\text { Tumor size } \\
(\mathrm{cm})\end{array}$} & \multicolumn{2}{|c|}{$\begin{array}{c}\text { Extent of liver } \\
\text { resection (segments) }\end{array}$} & \multicolumn{2}{|c|}{$\begin{array}{l}\text { Tumor capsule } \\
\text { invasion }\end{array}$} & \multicolumn{2}{|c|}{$\begin{array}{l}\text { Tumor } \\
\text { thrombus }\end{array}$} & \multicolumn{2}{|c|}{$\begin{array}{l}\text { Operating time } \\
\qquad(\min )\end{array}$} \\
\hline & $\geq 5$ & $<5$ & $\geq 1$ & $<1$ & Yes & No & Yes & No & $\geq 100$ & $<100$ \\
\hline Treatment $(n=63)$ & 18 & 45 & 21 & 42 & 53 & & 5 & 58 & 13 & 50 \\
\hline Control $(n=102)$ & 34 & 68 & 36 & 66 & 78 & 24 & 11 & 91 & 27 & 75 \\
\hline$\chi^{2}$ value & 0.409 & & & 0.066 & 1.395 & & 0.361 & & 0.722 & \\
\hline$p$-Value & 0.522 & & & 0.797 & 0.237 & & 0.548 & & 0.395 & \\
\hline
\end{tabular}

Table IV. Comparison of liver function and coagulation function of the two groups twelve months after surgery

\begin{tabular}{|c|c|c|c|c|c|}
\hline Group & Post-operative time (months) & TBIL (umol/l) & $\operatorname{ALB}(\mathrm{g} / \mathrm{l})$ & ALT (IU/1) & PT (s) \\
\hline \multirow[t]{3}{*}{ Treatment group $(n=63)$} & 1 & $50.6 \pm 10.1$ & $29.3 \pm 2.5$ & $35.3 \pm 16.1$ & $13.1 \pm 2.0$ \\
\hline & 6 & $43.2 \pm 11.4^{\mathrm{a}}$ & $30.3 \pm 2.7$ & $66.3 \pm 36.3$ & $14.2 \pm 1.6$ \\
\hline & 12 & $29.6 \pm 15.1^{b}$ & $38.3 \pm 1.5^{\mathrm{c}}$ & $48.3 \pm 19.7^{\mathrm{d}}$ & $13.2 \pm 1.0^{\mathrm{f}}$ \\
\hline \multirow[t]{3}{*}{ Control group $(n=102)$} & 1 & $52.3 \pm 15.3^{\mathrm{a}}$ & $28.8 \pm 6.5$ & $37.3 \pm 16.2$ & $13.6 \pm 1.2$ \\
\hline & 6 & $48.9 \pm 20.8$ & $29.3 \pm 3.1$ & $77.3 \pm 47.0$ & $14.0 \pm 1.8$ \\
\hline & 12 & $43.2 \pm 20.9^{b}$ & $30.2 \pm 3.6^{\mathrm{c}}$ & $114.3 \pm 19.3^{\mathrm{d}}$ & $15.1 \pm 1.7^{f}$ \\
\hline \multirow[t]{2}{*}{$t$-Value } & & a: 1.974 & c: 16.957 & $\mathrm{~d}: 21.17$ & f: 8.047 \\
\hline & & b: 4.489 & $\mathrm{c}:<0.001$ & $\mathrm{~d}:<0.001$ & $\mathrm{f}:<0.001$ \\
\hline \multirow[t]{2}{*}{$p$-Value } & & a: 0.048 & & & \\
\hline & & b: 0.00067 & & & \\
\hline
\end{tabular}

TBIL: Total bilirubin, ALB: albumin, ALT: alanine aminotransferase, PT: prothrombin time.

(PT).There was no statistically significant difference between the two groups $(p>0.05)$ for these measures (Table II).

Comparison of operative and pathological characteristics of the two groups. There was no statistically significant difference between the two groups in regard to tumor size, tumor capsule, tumor thrombus, range of liver resection, or operative time $(p>0.05)$ (Table III).

Comparison of liver and coagulation functions of the two groups 12 months after surgery. The liver function in the treatment group was better than that in the control group at 12 months after surgery. Compared with the control group, the TBIL in the treatment group was better 6 and 12 months after surgery $(p<0.05$ and $p<0.001$, respectively). Compared to the control group, ALB, ALT and PT in the treatment group was improved 12 months after surgery $(p<0.001)$ (Table IV).

Comparison of HBV-DNA activation, tumor recurrence, and AFP after surgery. In the treatment group, two cases $(3.17 \%)$ presented with HBV-DNA activation, while there were 13 cases $(12.75 \%)$ who presented with HBV-DNA activation in the control group; this difference was statistically significant $(p<0.05)$. There were 51 cases of tumor recurrence in the Table V. Comparison of follow-up data after surgery.

\begin{tabular}{lcccc}
\hline Group & $\begin{array}{c}\text { HBV-DNA } \\
\text { activation } \\
(\mathrm{n})\end{array}$ & \begin{tabular}{c} 
Tumor \\
recurrence \\
\cline { 4 - 5 }
\end{tabular} & $(\mathrm{n})$ & \multicolumn{2}{c}{ AFP ng/ml) } \\
\hline Treatment $(\mathrm{n}=63)$ & 2 & 23 & 12 & 5300 \\
Control $(\mathrm{n}=102)$ & 13 & 51 & 46 & 56 \\
$\mathrm{x}^{2}$ value & 4.316 & 2.866 & 11.594 & \\
$p$-Value & 0.038 & 0.090 & 0.001 & \\
\hline
\end{tabular}

AFP: Alpha fetoprotein.

control group, which was clearly higher than that in the treatment group $(n=23)$, a difference which was statistically significant $(p<0.05)$. In the treatment group, 12 cases (19.04\%) had improved AFP ( $\geq 400 \mathrm{ng} / \mathrm{ml}$ ) compared to 46 cases $(45.10 \%)$ in the control group; this difference was statistically significant $(p<0.001)$ (Table V).

Comparison of 3-year cumulative survival time and tumor recurrence rate after surgery. In the control group, postoperative 1-, 2-and 3-year cumulative survival rates were 


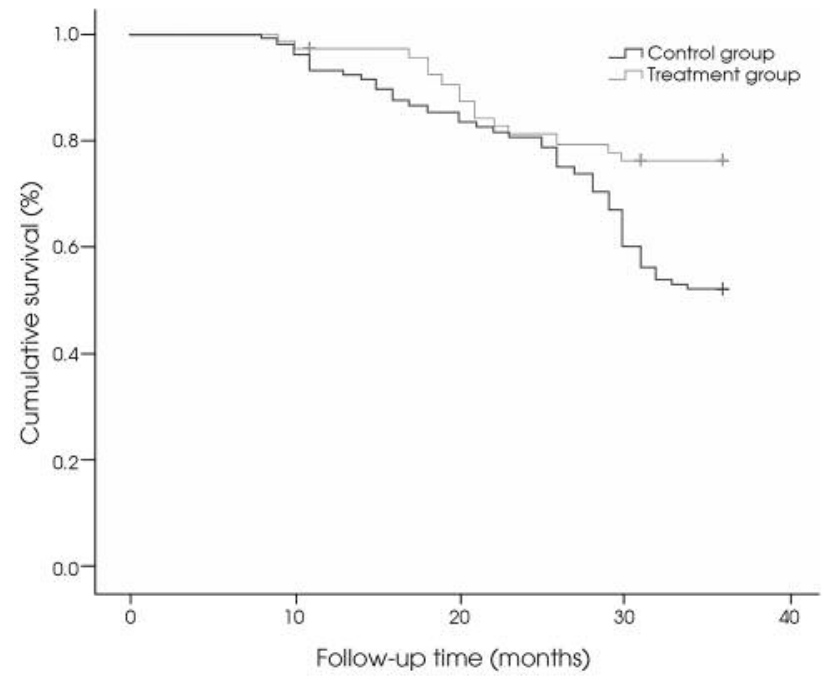

Figure 1. Comparison of postoperative cumulative overall survival rates between the two groups.

$94.12 \%, 81.37 \%$ and $52.94 \%$, respectively. In the treatment group, the corresponding rates were $93.65 \%, 77.78 \%$ and $71.43 \%$, respectively (Chi-square $=7.500, p=0.006)$ (Figure 1$)$.

In the control group, postoperative 1-, 2- and 3-year disease-free survival rates were $92.16 \%, 73.53 \%$ and $46.08 \%$, respectively. In the treatment group, the corresponding rates were $90.48 \%, 63.84 \%$ and $57.14 \%$, respectively. There was no statistical difference between the two groups (chisquared $=1.434, p=0.231$ ) (Figure 2).

\section{Discussion}

Primary liver cancer is one of the most common malignant tumors in China. In the 1990s, the mortality of liver cancer ranked second place among all cancer. There were 250,000 new cases around the world per year, with $43.7 \%$ cases occurring in China. Clinically, more than $90 \%$ of liver cancer presents as HCC. The etiology of liver cancer is mainly hepatitis virus infection, aflatoxin contamination in food, chronic alcoholism, autoimmune disease and cryptogenic cirrhosis. In China, the principal cause of liver cancer is hepatitis virus infection; China has a high incidence of HCC and high incidence of HBV. There are more than 130 million patients with HBV infection and $90 \%$ of patients with liver cancer have an accompanying HBV infection in China. Replication of HBV leads to the following three stages in sequence: hepatitis, cirrhosis, HCC (1-3). It was pointed out at the WHO Liver Cancer Prevention Conference that HBV infection has a very close relationship with liver cancer, with association in up to $80 \%$ of cases. Surgery is the optimal

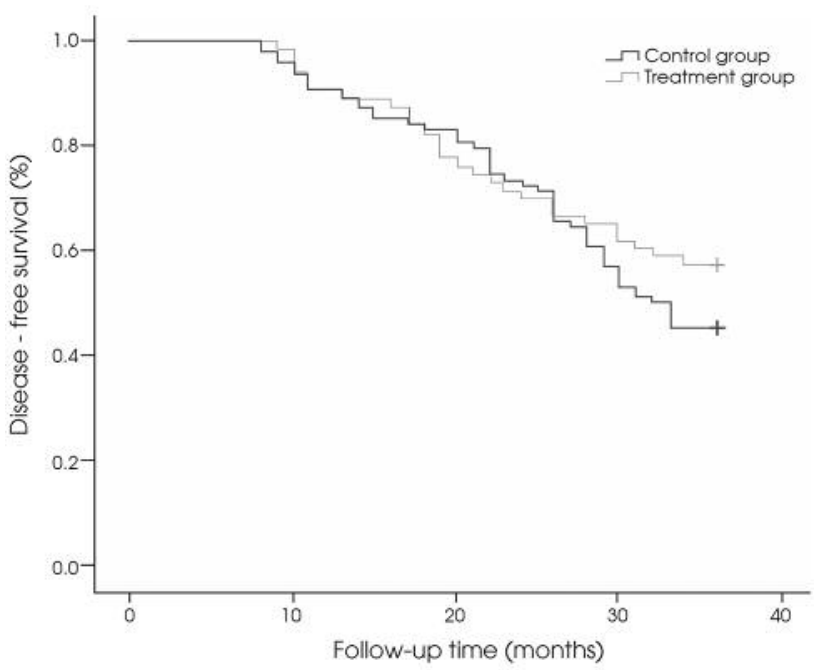

Figure 2. Comparison of postoperative disease-free survival rate between two groups.

treatment for liver cancer, but rates of postoperative recurrence and metastasis are very high, which is correlated with tumor size, location, portal vain tumor thrombus, differentiation and age. Added to this, HBV replication is most important in HBV-related liver cancer (4-6). The treatment of HBV in patients with liver cancer was often neglected in the past, especially in the perioperative period.

It has been reported that the HBV status of a patient has an important influence on tumor recurrence. In the case of two patients with the same level of liver cancer differentiation, cancer tissue with a high HBV-DNA load showed higher invasion due to the fact that high HBV-DNA replication reduces immune surveillance of tumor cells (7-10). A high viral load and $\mathrm{HBeAg}$-positive status are the main virological factors associated with HBV-related HCC recurrence $(11,12)$. A consensus has been reached that antiviral treatment should be undertaken for HBV-related HCC if HBV-DNA is positive following comprehensive treatment for HCC (13). Antiviral treatment with other therapies could effectively reduce the viral load, tumor recurrence and metastasis, prolong patient survival time and improve their quality of life.

With the improvement of postoperative tumor recurrence, much attention has been focused on postoperative HBV reactivation in HBV-related HCC, which has been a common clinical puzzle. Some clinical studies have shown that some patients with HBV-related HCC who were HBV-DNA negative did not achieve the expected surgical outcomes since HBV was still in the activated replication state. Surgical treatment led to activation of HBV and increased HBV replication, which increased the damage to the liver $(14,15)$. 
Whether antiviral treatment for HCC with negative HBVDNA is essential needs to be solved. To explore this clinical problem, we divided patients with $\mathrm{HCC}$ negative for 'HBVDNA into a treatment group $(n=63)$ and control group $(n=102)$ according to whether they would receive antiviral treatment. There was no statistical difference in liver function, tumor pathological biological characteristics, operating time or coagulation function between the groups. After a 1-year follow-up, it was found that the postoperative liver function in the treatment group was significantly better than that in the control group, including TBIL, ALB, ALT and PT.

HBV reactivation is usually defined as being when patients with chronic or past $\mathrm{HBV}$ infection demonstrate an increase in HBV viral replication, HBV-DNA, by at least 10 -fold or an absolute increase to $>10^{9}$ copies $/ \mathrm{ml}$, as well as transformation from HBV-DNA-negative to HBV-DNA-positive. Some patients with HBV-related HCC preoperatively negative for HBV-DNA demonstrated postoperative HBV reactivation. The mechanism involved here is the presence of covalently closed circular DNA in the hepatocyte nucleus (16-19). Our results support the view that antiviral therapy should be a common therapy before and after surgery in patients with HCC negative for HBV-DNA.

$\mathrm{HBV}$ infection is the main cause of primary HCC in China. High viral load is the most important factor which affects the occurrence, development and prognosis of HCC. It was reported that surgery, chemotherapy, radiotherapy, etc. had the potential to reactivate $\mathrm{HBV}$,which reduced the effects of antitumor treatment $[36 \% \mathrm{HBV}$ reactivation in systemic chemotherapy (20), $15-30 \%$ in percutaneous hepatic artery embolization (21$23), 21.8 \%$ in radiotherapy $(24,25)]$. Postoperative HBV reactivation rate in patients with $\mathrm{HBV}$-related $\mathrm{HCC}$ after radical resection was $12.75 \%$ in our study, which was higher than the $2 \%$ reported by a smaller study (26). No similar reports on large patient samples are available inside or outside of China. Surgery itself can also reactivate $\mathrm{HBV}$ of patients with a low viral load (HBV-DNA $<2,000 \mathrm{IU} / \mathrm{ml}$ ), which leads to a significant decrease of overall survival and disease-free survival rates in patients without $\mathrm{HBV}$ reactivation. Therefore, it is still a controversy in clinical practice as to whether antiviral therapy should become a regular treatment for HBV-related HCC negative for HBV-DNA.

The survival results of our study support the notion that antiviral therapy should become a regular treatment for HBV-related HCC negative for HBV-DNA before and after surgery. Although there was no statistical difference in disease-free survival rates between the two groups, we could conclude that the small number of cases led to this, larger studies are clearly needed in the future.

There are few reports about $\mathrm{HBV}$ reactivation after surgery of patients with HBV-related HCC, negative for HBV-DNA which needs more investigation. In conclusion, we demonstrated that antiviral treatment for HBV-related HCC negative for HBV-DNA is beneficial for liver function, the status of coagulation function, disease control, prevention of tumor recurrence, the improvement of quality of life, reduction of death rate and the prolongation of survival time.

\section{Conflicts of Interest}

The Authors declare that they have no competing interests in regard to this study.

\section{Acknowledgements}

The work was supported by grants from the Science Foundation of Yantai (2016WS015).

\section{References}

1 Croagh CM, Desmond PV and Bell SJ: Genotypes and viral variants in chronic hepatitis B: A review of epidemiology and clinical relevance. World J Hepatol 7: 289-303, 2015.

2 Goh GB, Chang PE and Tan CK: Changing epidemiology of hepatocellular carcinoma in Asia. Best Pract Res Clin Gastroenterol 29: 919-928, 2015.

3 Yang JD and Roberts LR: Hepatocellular carcinoma: A global view. Nat Rev Gastroenterol Hepatol 7: 448-458, 2010.

4 Chuma M, Hige S, Kamiyama T, Meguro T, Nagasaka A, Nakanishi K, Yamamoto Y, Nakanishi M, Kohara T, Sho T, Yamamoto K, Horimoto H, Kobayashi T, Yokoo H, Matsushita M, Todo S and Asaka M: The influence of hepatitis B DNA level and antiviral therapy on recurrence after initial curative treatment in patients with hepatocellular carcinoma. J Gastroenterol 44: 991-999, 2009.

5 Rahbari NN, Mehrabi A, Mollberg NM, Muller SA, Koch M, Buchler MW and Weitz J: Hepatocellular carcinoma: current management and perspectives for the future. Ann Surg 253: 453469, 2011.

6 Yang SC, Lee CM, Hu TH, Wang JH, Lu SN, Hung CH, Changchien $\mathrm{CS}$ and Chen $\mathrm{CH}$ : Virological response to entecavir reduces the risk of liver disease progression in nucleos(t)ide analogue-experienced $\mathrm{HBV}$-infected patients with prior resistant mutants. J Antimicrob Chemother 68: 2154-2163, 2013.

7 Chong CC, Wong GL and Lai PB: Impact of antiviral therapy on post-hepatectomy outcome for hepatitis B-related hepatocellular carcinoma. World J Gastroenterol 20: 6006-6012, 2014.

8 Ishikawa T: Antiviral therapy to reduce recurrence and improve survival in hepatitis B virus-related hepatocellular carcinoma. World J Gastroenterol 19: 8861-8866, 2013.

9 Kubo S, Takemura S, Sakata C, Urata Y and Uenishi T: Adjuvant therapy after curative resection for hepatocellular carcinoma associated with hepatitis virus. Liver Cancer 2: 40-46, 2013.

10 Qu LS, Jin F, Huang XW and Shen XZ: High hepatitis B viral load predicts recurrence of small hepatocellular carcinoma after curative resection. J Gastrointest Surg 14: 1111-1120, 2010.

11 Chen CJ, Yang HI, Iloeje UH and Group R-HS: Hepatitis B virus DNA levels and outcomes in chronic hepatitis B. Hepatology 49: S72-84, 2009.

12 Zhou Y, Zhang Z, Zhao Y, Wu L and Li B: Antiviral therapy decreases recurrence of hepatitis $B$ virus-related hepatocellular carcinoma after curative resection: a meta-analysis. World J Surg 38: 2395-2402, 2014. 
13 Kubo S, Takemura S, Tanaka S, Shinkawa H, Nishioka T, Nozawa A, Kinoshita M, Hamano G, Ito T and Urata Y: Management of hepatitis B virus infection during treatment for hepatitis B virus-related hepatocellular carcinoma. World J Gastroenterol 21: 8249-8255, 2015.

14 Chen L, Zhang Q, Chang W, Du Y, Zhang H and Cao G: Viral and host inflammation-related factors that can predict the prognosis of hepatocellular carcinoma. Eur J Cancer 48: 19771987, 2012.

15 Yang T, Lu JH, Zhai J, Lin C, Yang GS, Zhao RH, Shen F and Wu MC: High viral load is associated with poor overall and recurrence-free survival of hepatitis B virus-related hepatocellular carcinoma after curative resection: a prospective cohort study. Eur J Surg Oncol 38: 683-691, 2012.

16 Hui CK, Bowden S, Jackson K, Au WY, Fong DY, Lie AK, Chim CS, Liang $\mathrm{R}$ and Lau GK: Clinical significance of intrahepatic hepatitis B virus covalently closed circular DNA in chronic hepatitis B patients who received cytotoxic chemotherapy. Blood 105: 2616-2617, 2005.

17 Li Q, Lu F, Deng G and Wang K: Modeling the effects of covalently closed circular DNA and dendritic cells in chronic HBV infection. J Theor Biol 357: 1-9, 2014.

18 Tseng TC and Kao JH: Treating Immune-tolerant Hepatitis B. J Viral Hepat 22: 77-84, 2015.

19 Yang HC and Kao JH: Persistence of hepatitis B virus covalently closed circular DNA in hepatocytes: molecular mechanisms and clinical significance. Emerg Microbes Infect 3: e64, 2014.

20 Yeo W, Lam KC, Zee B, Chan PS, Mo FK, Ho WM, Wong WL, Leung TW, Chan AT, Ma B, Mok TS and Johnson PJ: Hepatitis B reactivation in patients with hepatocellular carcinoma undergoing systemic chemotherapy. Ann Oncol 15: 1661-1666, 2004.

21 Jang JW, Choi JY, Bae SH, Kim CW, Yoon SK, Cho SH, Yang JM, Ahn BM, Lee CD, Lee YS, Chung KW and Sun HS: Transarterial chemo-lipiodolization can reactivate hepatitis $B$ virus replication in patients with hepatocellular carcinoma. J Hepatol 41: 427-435, 2004.
22 Park JW, Park KW, Cho SH, Park HS, Lee WJ, Lee DH and Kim CM: Risk of hepatitis B exacerbation is low after transcatheter arterial chemoembolization therapy for patients with HBV-related hepatocellular carcinoma: report of a prospective study. Am J Gastroenterol 100: 2194-2200, 2005.

23 Peng JW, Lin GN, Xiao JJ and Jiang XM: Hepatitis B virus reactivation in hepatocellular carcinoma patients undergoing transcatheter arterial chemoembolization therapy. Asia Pac J Clin Oncol 8: 356-361, 2012.

24 Jang JW, Kwon JH, You CR, Kim JD, Woo HY, Bae SH, Choi JY, Yoon SK and Chung KW: Risk of HBV reactivation according to viral status and treatment intensity in patients with hepatocellular carcinoma. Antivir Ther 16: 969-977, 2011.

25 Kim JH, Park JW, Kim TH, Koh DW, Lee WJ and Kim CM: Hepatitis B virus reactivation after three-dimensional conformal radiotherapy in patients with hepatitis B virus-related hepatocellular carcinoma. Int J Radiat Oncol Biol Phys 69: 813-819, 2007.

26 Huang L, Li J, Lau WY, Yan J, Zhou F, Liu C, Zhang X, Shen J, $\mathrm{Wu} \mathrm{M}$ and Yan Y: Perioperative reactivation of hepatitis B virus replication in patients undergoing partial hepatectomy for hepatocellular carcinoma. J Gastroenterol Hepatol 27: 158-164, 2012.
Received May 19, 2017

Revised June 14, 2017

Accepted June 16, 2017 